\title{
O núcleo de estudo sobre justiça restaurativa e de práticas restaurativas: uma análise do projeto do município de Socorro, São Paulo
}

\section{The study nucleus on restorative justice and restorative practices: an analysis of the project of the municipality of Socorro, São Paulo}

Fernanda Yumi Furukawa Hata ${ }^{1}$

Diego Dall'Agnol Maia²

\begin{abstract}
Resumo: Neste artigo refletimos acerca da sensibilização a respeito da Justiça Restaurativa e implantação de práticas restaurativas na cidade de Socorro, São Paulo, com o objetivo de ser desenvolvida, para o sistema de justiça e para a comunidade local, uma alternativa serva para solucionar conflito sociais envolvendo casos judicializados ou não. Neste sentido, realizamos uma descrição e análise sobre as etapas percorridas para sensibilizar os munícipes da cidade de Socorro/SP, bem como para que fosse possível implantar um núcleo para estudo sobre justiça restaurativa e desenvolvimento de práticas restaurativas. Buscou-se também analisar as dificuldades enfrentadas na compreensão a respeito do objetivo do projeto desenvolvido na cidade, bem como a dificuldade de motivar os membros da comunidade a darem o apoio necessário para o amadurecimento do projeto. Ao final, apresentamos a descrição e análise do primeiro curso realizado na cidade de Socorro/SP, como o objetivo de formar facilitadores em Práticas Circulares, assim como é apresentado os resultados obtidos após esta importante etapa que acreditamos ter sido capaz de mobilizar os membros da comunidade sobre a possibilidade e capacidade de lidar com situações de conflito social sem a interferência da coercitividade ou coação.
\end{abstract}

Palavras-chave: justiça restaurativa, núcleo de estudo, prática circular.

Abstract: In this article we reflect on the sensitization about Restorative Justice and implementation of restorative practices in the city of Socorro, São Paulo,

\footnotetext{
${ }^{1}$ Juíza de Direito do Tribunal de Justiça do Estado de São Paulo (TJSP). Mestre em Direito Penal pela Pontifícia Universidade Católica de São Paulo (PUCSP). Especialista em Direito Penal pela Universidade de Salamanca (ESP). Formação em Princípios, Teoria e Aplicações da Justiça Restaurativa pela Eastern Mennonite University (EMU/EUA). Facilitadora em Justiça Restaurativa pela Escola Superior da Magistratura do Rio Grande do Sul (AJURIS). Fundadora do Núcleo de Estudo e Práticas Restaurativas de Socorro (NEPRES). Facilitadora em Constelação Familiar. Discente do curso de Psicologia pela Universidade São Francisco (USF). E-mail: fernandayumi@yahoo.com.br

${ }^{2}$ Advogado. Mestrando em Filosofia do Direito pela Pontifícia Universidade Católica de São Paulo (PUCSP). Especialista em Direito Público com ênfase em Direito Administrativo e Direito Constitucional pela Pontifícia Universidade Católica de Campinas (PUCCAMP). Formação em Princípios, Teoria e Aplicações da Justiça Restaurativa pela Eastern Mennonite University (EMU/EUA). Facilitador em Justiça Restaurativa pela Escola Superior da Magistratura do Rio Grande do Sul (AJURIS). Membro do Fórum Europeu para Justiça Restaurativa (EFRJ). Voluntário no Núcleo de Estudo e Práticas Restaurativas de Socorro (NEPRES). E-mail: ddam.diego@gmail.com
} 
with the objective of developing, for the justice system and the local community, a useful alternative to solve social conflicts involving judicial cases or not. In this sense, we performed a description and analysis of the steps taken to sensitize the residents of the city of Socorro / SP, as well as to establish a nucleus for study on restorative justice and development of restorative practices. It was also sought to analyze the difficulties faced in understanding the objective of the project developed in the city, as well as the difficulty of motivating the members of the community to give the necessary support for the maturing of the project. At the end, we present the description and analysis of the first course held in the city of Socorro / SP, as the objective to train facilitators in Circular Practices, as well as the results obtained after this important stage that we believe have been able to mobilize the members of community about the possibility and ability to deal with situations of social conflict without the interference of coercion.

Keywords: restorative justice, nucleus of study, circular practice.

\section{Introdução}

$\mathrm{Na}$ cidade de Socorro, apesar de ser uma localidade privilegiada no Circuito das Águas e das Malhas, composta pelas cidades de Águas de Lindóia, Amparo, Holambra, Jaguariúna, Lindóia, Monte Alegre do Sul, Pedreira, Serra Negra e Socorro, no Estado de São Paulo, são abundantes as situações de conflito envolvendo disputas familiares, guarda e alimentos, violência na escola, violência doméstica, embriaguez ao volante, furtos, roubos, tráfico de drogas e drogadição.

As dificuldades advindas dos relacionamentos sociais era algo já analisada desde 2010, sendo que desde então era algo espantoso identificar que a decisão judicial não solucionava o conflito, algumas famílias estavam envolvidas em mais de um processo, sendo que foi possível nestes últimos oito anos, verificar que a litigiosidade atingia as pessoas em graus desconhecidos no processo, tanto que algumas partes eram conhecidas pelo nome diante da repetição de demandas em que elas estavam envolvidas.

Tal insuficiência do trabalho no meio jurídico gerou uma busca de formas de lidar com estas situações de conflito vivenciadas pelos cidadãos, o que inicialmente foi feito por meio da capacitação em cursos particulares diversos, e depois em uma pesquisa e leitura sobre o que outros operadores do Direito estavam realizando.

Atualmente, os esforços se concentram no estudo sobre a Justiça Restaurativa e as suas aplicações práticas como uma forma de dar voz às partes integrantes do processo judicial, refletir sobre as experiências de injustiças e quais são as necessidades 
que surgem quando desejamos que haja justiça nas soluções de situações de conflito.

Neste artigo, partimos da análise do projeto de Justiça Restaurativa que teve início no primeiro semestre de 2017, na cidade de Socorro/SP: o Núcleo de Estudo e Práticas Restaurativas de Socorro (NEPRES). Analisa-se a sensibilização da comunidade, a implantação, a estruturação e a capacitação de facilitadores para atuar no projeto, bem como apresenta os resultados obtidos por meio de seus fluxos e procedimentos.

O município de Socorro possui aproximadamente quarenta mil habitantes, desfrutando de um sistema de justiça composto por duas Varas Judiciais, duas Promotorias de Justiça, uma Delegacia da Polícia Civil. Conta ainda com a Subseção da Ordem dos Advogados do Brasil, um CAPS (Centro de Atenção Psicossocial), um CRAS (Centro de Referência de Assistência Social), um CREAS (Centro de Referência Especializada de Assistência Social), um CEMEP (Centro Municipal de Ensino Profissionalizante) e Fundo Social de Solidariedade, bem como do Conselho da Comunidade.

Apesar desta estrutura, a Justiça Restaurativa, que é inspirada em um ideal de que o sistema de justiça seja organizado por meio de uma base comunitária, paritário e inclusivo no tratamento, voltado para a promoção da paz e a compreensão da responsabilização individual e coletiva para que seja mantida a estabilidade social, ainda não conseguiu sensibilizar e conquistar a colaboração total desta rede, apesar dos diversos ofícios enviados no início do trabalho e dos contatos internos da eficiente rede municipal.

Infelizmente, questões que ultrapassam a reflexão sobre a justiça, como por exemplo, a dificuldade de liberação pelos superiores, a fixação de honorários para o advogado ou os discursos produzidos pelo senso comum, que creditam à Justiça Restaurativa um tratamento mais brando no processo penal, continuam dificultando a exata compreensão a respeito dos objetivos do NEPRES.

Para a sensibilização e a implantação do projeto, não houve o recebimento de qualquer recurso estatal ou de doações. O investimento partiu exclusivamente da Juíza da 1․ Vara Judicial da Comarca de Socorro, que destinou recursos para que fosse possível manter a periodicidade dos encontros do NEPRES e para capacitar facilitadores em Prática Circular, que pudessem atuar em círculos restaurativos e auxiliar lideranças locais a levar o projeto para além do sistema de justiça. 
Inicialmente, foi possível realizar a capacitação de cinco voluntários em Prática Circular, por meio do curso oferecido pela Escola Paulista da Magistratura de São Paulo, que ficaram encarregados de realizar os primeiros círculos de construção de paz na cidade de Socorro. Salientamos, que o curso foi pago pelos voluntários e que foi possível obter o transporte para Campinas por meio do Município de Socorro, que auxiliou nesta formação.

Os facilitadores indicados para esta formação receberam a capacitação para operacionalizar e pensar a logística de implementação dos círculos restaurativos na cidade de Socorro, tanto para situações em que exista um conflito ou não, bem como para promover os princípios da Justiça Restaurativa para a sensibilização da comunidade local.

Contudo, ter apenas cinco facilitadores em práticas circulares ainda era insuficiente para a demanda apresentada pela cidade, bem como considerando as questões financeiras, posto que os facilitadores são voluntários e exigir deles o pagamento do curso e os custos com alimentação, bem como a insuficiente formação de alguns cursos que não disponibilizam a identificação da formação dos professores, fizeram surgir a necessidade de promoção do Primeiro Curso de Formação de Facilitadores em Prática Restaurativa, no ano de 2018, ofertando 15 (quinze) vagas para o público em geral.

Em julho de 2018, foi realizada a formação de facilitadores em Prática Circular que receberam a capacitação teórica sobre o que é a Justiça Restaurativa e os fundamentos da Prática Circular, bem como o treinamento prático para facilitar os círculos de construção de paz e a supervisão das 3 (três) primeiras atividades não conflitivas e conflitivas.

Por fim, que é digno de ser aqui compartilhado, e, quem sabe, buscar críticas para o aprimoramento e servir de inspiração para outras localidades, conforme anotações que seguem abaixo. seguindo para a descrição e análise do projeto desenvolvido e da intervenção realizada na comunidade de Socorro/SP, destaca-se que que o NEPRES continua buscando formas de evoluir e apreender novas formas para sensibilizar a comunidade local sobre a importância da Justiça Restaurativa, apesar de já ter ocorrido um importante avanço. 


\section{O Núcleo De Estudo e Práticas Restaurativas de Socorro (SP)}

A Justiça Restaurativa, no Brasil, começou a ser implementada por meio da ação conjunta entre o Ministério da Justiça e dos Tribunais de Justiça dos Estados do Distrito Federal, do Rio Grande do Sul e de São Paulo. No ano de 2005, foi dado início a três projetos pilotos com financiamento da Secretaria de Reforma do Judiciário, bem como pelo Programa das Nações Unidas para o Desenvolvimento, este que realiza o monitoramento do cumprimento das dezessete metas do desenvolvimento sustável das Nações Unidas $^{3}$.

Após a implementação e execução dos três projetos pilotos, o passo mais importante dado em favor da Justiça Restaurativa no Brasil ocorreu no dia 31 de maio de 2016 , quando foi editada a Resolução n 225 do Conselho Nacional de Justiça, dispondo sobre a Política Nacional de Justiça Restaurativa no âmbito do Poder Judiciário. A Resolução foi um importante passo para a expansão da Justiça Restaurativa no Brasil, pois foi por meio dela que houve a sistematização dos elementos constitutivos das práticas restaurativas e a estruturação para a implementação e execução de projetos no âmbito do Poder Judiciário.

Foi a partir deste movimento nacional que surgiu o Núcleo de Estudo e Práticas Restaurativas de Socorro (NEPRES). No dia 12 de maio de 2017, por meio da iniciativa da Juíza Fernanda Yumi Furukawa Hata, da $1^{\text {a }}$ Vara da Comarca de Socorro (SP), e da Assistente Social Célia Regina de Biasi Arelaro, do Judiciário de Socorro (SP), foi realizado o primeiro encontro discutir e fundar o NEPRES, com o objetivo de difundir o conhecimento, a capacitação e o desenvolvimento de práticas relacionadas com a justiça restaurativa e a atuação como grupo gestor.

Apesar do intenso movimento judicial, o trabalho há quase três anos na cidade de Socorro permitiu apurar a necessidade de um outro olhar para a população, em especial considerando que a Juíza Titular da $2^{\underline{a}}$ Vara de Socorro e um dos Promotores de Justiça estão na cidade há mais de 15 anos, o que demonstra a dedicação e o interesse que o operador do Direito tem com a localidade.

\footnotetext{
${ }^{3} \mathrm{~A}$ justiça restaurativa compõe a meta 16 : Promover sociedades pacíficas e inclusivas para o desenvolvimento sustentável, proporcionar o acesso à justiça para todos e construir instituições eficazes, responsáveis e inclusivas em todos os níveis. (UN, 2015)
} 
Com isto e em razão do incentivo da Coordenadoria da Infância e Juventude do Tribunal de Justiça do Estado de São Paulo, Grupo de Justiça Restaurativa, deu à Assistente Social Celia com base no grupo de estudos realizado em outra cidade paulistana, inicia-se o grupo de estudos mensais que dará origem ao NEPRES.

Além do contato direto e pessoal que a cidade permite, foram enviados vários ofícios por meio da Juíza convidando integrantes da comunidade para participar do projeto e com isto, conseguimos formar um grupo multi e interdisciplinar formado por operadores do Direito, psicólogos, assistentes sociais, funcionários do Tribunal de Justiça, funcionários do Município e cidadãos em geral.

Foram realizados encontros nos seguintes dias: 12.05.2017, 09.06.2017, 26.06.2017, 04.08.2017, 04.09.2017, 02.10.2018, 17.11.2017, 04.12.2017, 26.02.2018, $26.03 .2018,19.04 .2018,14.05 .2018,25.06 .2018,13.08 .2018,24.09 .2018$, todos com duração de 3 ou 4 horas, sendo que no encontro de dezembro de 2017 contamos com a presença do Alexandro Pedroso de Souza e Luis Alexandre Faulim, guardas municipais de Laranjal Paulista que apresentaram como funciona a Justiça Restaurativa no Município paulista de origem.

Atualmente, o NEPRES possui um planejamento pedagógico elaborado a partir das pesquisas desenvolvidas pelos principais autores que produzem críticas sobre a Justiça Restaurativa, como por exemplo, Howard Zerh, John Braithwaite, Kathleen Daly, Martin Wright, Joanna Shapland, Declan Roche, Nils Christie e Albert Dzur, sempre buscando relacionar o estudo teórico com as questões práticas que afetam a cidade de Socorro. Do mesmo modo, o projeto pedagógico tem priorizado o desenvolvimento de práticas restaurativas por meio do Círculo de Construção da Paz, metodologia desenvolvida por Kay Pranis.

Além disto, o ano de 2017 foi realizado com base em exposição de aulas e temas da Justiça Restaurativa e no ano de 2018, com base no grupo, invertermos a lógica expositiva e os integrantes passaram a apresentar exposições sobre o tema, bem como sugeriram a temática do segundo semestre de 2018: Justiça Restaurativa e a Mulher.

Além disto, no mês de julho de 2018, foi promovido o primeiro curso de formação de facilitadores em prática restaurativa com ênfase em processos circulares. Por meio 
deste projeto foi possível a capacitação de quinze novos facilitadores para atuarem como voluntários no NEPRES, aumentando o quadro para um total de vinte e dois facilitadores à disposição da comunidade de Socorro.

Porém, mesmo neste cenário de desenvolvimento, muitos desafios surgiram e continuam surgindo, de forma que para que o projeto seja mantido na cidade de Socorro faz-se necessário a contínua avaliação e reorganização sempre tendo por base a autoanálise e autogestão do grupo, razão pela qual se propõe a análise destes desafios a seguir.

\section{A Sensibilização da Comunidade para Compreender o que é a Justiça Restaurativa}

A sensibilização da comunidade continua sendo um dos grandes desafios para a implementação da Justiça Restaurativa e para a execução das práticas restaurativas. Por mais que sejam realizadas ações para conscientizar a comunidade sobre o tema, por exemplo, reuniões mensais explorando os diversos temas que podem ser analisados a partir da perspectiva da Justiça Restaurativa, o discurso preponderante continua sendo de que a Justiça Restaurativa é uma proposta de flexibilização da justiça criminal - um tratamento mais brando para os ofensores.

Além de não existir conceito unânime do que seria a Justiça Restaurativa, fato aliás inconcebível com a temática, pois se trata de um conceito em construção, verifica-se que os conceitos existentes não explicam suficientemente o que seria esta abordagem, o que causa certa estranheza para quem não conhece e para quem não estuda o tema é rápida a ligação com a mediação, a conciliação e até a constelação familiar.

No projeto que está sendo desenvolvido em Socorro, por meio do NEPRES, é possível identificar nas ações de sensibilização que o debate em torno da Justiça Restaurativa sempre é recepcionado como um tema entrelaçado com às questões da criminologia, especialmente no que diz respeito a punição e ao encarceramento ou que tem ligação com a conciliação.

Portanto, o primeiro grande desafio do NEPRES foi difundir a Justiça Restaurativa como uma reflexão sobre o que é a justiça, incentivando o debate amplo com a parti- 
cipação de diversos atores sociais em busca de respostas sobre as diferentes formas de respostas que podem ser dadas quando um dano ocorre e prejudica a estabilidade social.

Buscou-se, por meio de ações de sensibilização da comunidade, expor que a justiça moderna propõe que o Estado deve agir em nome das vítimas, promovendo uma resposta ao dano causado e dissuadindo ações que causem danos no futuro (ZEHR, 1990). Apresentou-se, também, que desde o final de 1980 esta abordagem da justiça moderna tem sido desafiada pela ideia de uma Justiça Restaurativa, que ganhou atenção mundial devido às deficiências e falhas do modelo convencional, que podem ser percebidos pela população na atuação dos sistemas de justiça.

Neste contexto, a ação de sensibilização da comunidade partiu do pressuposto de que a Justiça Restaurativa é vista como uma filosofia complexa e em evolução, motivo pelo qual existem muitas formas diferentes de ser explicada ao redor do mundo (SHAPLAND et al. 2007), mas que didaticamente poderia ser explicada como uma nova maneira de pensar sobre o que é a justiça a partir da possibilidade de reconciliação entre as partes envolvidas em um conflito, por meio de um procedimento que permite o papel ativo das partes e a construção conjunta da decisão.

Portanto, a sensibilização da comunidade de Socorro, para compreender o que é a Justiça Restaurativa, tenta difundir um novo olhar para a maneira de como pensamos sobre a justiça. Por meio das ações do NEPRES, está se propondo para a comunidade uma oportunidade para refletirmos sobre nossos afetos reativos - nossas necessidades - que nos fazem desejar a justiça. Procura-se, neste processo de sensibilização, apresentar a possibilidade de implantação de um processo dialógico - entre vítimas e ofensores - capaz de promover transformações no sistema jurídico, político, familiar entre outros (DALY, 2006), tornando todos responsáveis pela manutenção da estabilidade social (Zehr, 1990; Zehr e Mika, 1998; Wright, 2007, 2008; Sawatsky, 2008; Pali, 2014).

\section{A Implantação do Núcleo de Estudo e Práticas Restaurativas}

O envolvimento da comunidade de Socorro com a Justiça Restaurativa, efetivamente, começou no ano de 2017. Contudo, anos antes já haviam sido realizadas algu- 
mas tentativas de sensibilização da comunidade por meio de palestras promovidas pelo Tribunal de Justiça do Estado de São Paulo, podendo-se citar os Seminários Internacionais de Justiça Restaurativa, a palestra realizada por um magistrado do Tribunal de Justiça em Socorro e também a iniciativa de alguns munícipes socorrenses de realizar cursos sobre o tema em São Paulo.

O movimento das fundadoras do NEPRES em conjunto com a sociedade faz parte do esforço entre muitos grupos e coletivos que estão em busca de alternativas para lidarcom conflitos que estão judicializados e outros que não estão, para que não seja necessária a coerção como medida solucionadora, para que seja possível a retomada do diálogo, da convivência dentro da comunidade e da retomada da paz social.

A Justiça Restaurativa, incialmente, foi pensada como uma estratégia para executar ações dentro da estrutura do Poder Judiciário da Comarca de Socorro. Porém, como a maior adesão ao projeto foi de voluntários de outros segmentos da sociedade, foi necessário pensar em uma nova estratégia que pudesse representar uma visão de "sociedade restaurativa".

Assim, iniciou-se no ano de 2017 a estruturação do núcleo de estudos com o objetivo de atrair a participação da população da cidade de Socorro para participar das exposições e debates sobre o que é a Justiça Restaurativa. Neste período, o núcleo de estudos contou com a participação, em média, de trinta pessoas por encontro.

Em contraposição aos demais grupos formados em especial em São Paulo, o grupo de Socorro era e continua formado por uma minoria graduada em Direito, o que auxiliou no estudo do Justiça Restaurativa que propõe a alteração do paradigma existente no ordenamento jurídico. Apesar da preocupação inicial, após os cursos realizados na Eastern Mennonite University, houve a compreensão que na verdade um grupo formado por pessoas da comunidade e com diversidade de conhecimentos era o ideal.

Com isto, prosseguimos buscando a formação de facilitadores, uma vez que apenas poderíamos contar com dois facilitadores em Justiça Restaurativa, sendo um deles a Juíza que não poderia facilitar os seus próprios processos.

Assim, em 2017, os primeiros voluntários foram encaminhados para o treinamento 
promovido pela Escola Paulista da Magistratura. Nesta primeira oportunidade, foram encaminhados oito participantes do NEPRES para serem treinados como facilitadores em círculos de construção de paz, com o objetivo de colaborarem com a comunidade de Socorro na construção de paz. Contudo, apenas um dos voluntários já tinha formação anterior, um voluntário não reside em Socorro e não voltou ao NEPRES e outro não deu seguimento aos trabalhos, razão pela qual apenas cinco novas facilitadoras passaram a formar o grupo de Socorro.

Saliento que em ainda não se sabem as causas, se por causa da deficiência do curso realizado ou se por medo desta nova prática, o início das facilitadoras foi muito dificultoso e apesar da solicitação de ajuda para realização de círculos foram necessários meses até que elas se dispusessem a fazer a prática que seria acompanhada da Juíza ou do facilitador que estava em sua segunda formação.

Quanto ao NEPRES, em 2018, foi observada a redução do número de participantes nas reuniões do núcleo de estudo. Uma hipótese que pode ser considerada, é que a redução dos participantes esteja relacionada com o esforço de sensibilização da comunidade para que ela compreenda que a implantação do NEPRES não se trata de um ideal voltado para o abolicionismo penal ou de uma oportunidade para o tratamento mais brando nos casos criminais, mas sim de um ideal que procura a construção de paz por meio da responsabilidade compartilhada e da manutenção do relacionamento entre os membros da sociedade.

Neste ponto, por meio da autoanálise verificou-se a necessidade de elaborar uma nova estratégia para o amadurecimento da Justiça Restaurativa na cidade de Socorro. Assim, partindo de uma revisão da metodologia dos trabalhos, iniciou-se um ciclo de descentralização das reuniões do NEPRES com a retirada do grupo do Fórum.

A primeira experiência foi realizada com a reunião do núcleo de estudos na Associação Comercial de Socorro, oportunidade em que não se observou o potencial de sensibilização da comunidade. A segunda experiência foi a realização do encontro na Associação dos Pais e Amigos dos Excepcionais de Socorro, ocasião em que foi possível desfrutar de uma profunda sensibilização dos membros do NEPRES, bem como da comunidade envolvida com a associação. Já a terceira experiência, foi a realização do 
encontro em escola particular, gratuitamente cedida para o encontro, mas que também não surtiu efeito em trazer a comunidade para dentro do grupo, razão pela qual devido a comodidade, os encontros voltaram a ocorrer dentro do Fórum de Socorro.

A nova estratégia adotada para a implantação da Justiça Restaurativa na cidade de Socorro foi frutífera, pois apesar de ter mobilizado em grau menor do que esperado a comunidade sobre o projeto que está sendo desenvolvido, foi possível identificar um maior envolvimento dos membros do NEPRES com questões sensíveis da comunidade. Deste modo, a nova metodologia trouxe aos participantes a consciência da responsabilidade compartilhada e motivação para apresentarem temas diversos para debater a partir da perspectiva da Justiça Restaurativa.

A autogestão ainda foi verificada na proposta de inversão da metodologia de estudo, com a apresentação de seminários e textos escritos sobre o tema da Justiça Restaurativa, bem como a escolha da temática do segundo semestre de 2018: Justiça Restaurativa e Mulher, sendo que esta alteração além de incentivar o estudo por parte dos integrantes, permitiu a divisão do "poder de fala" e também o acréscimo decorrentes dos conhecimentos e experiências pessoais deste grupo tão diverso.

A responsabilidade compartilhada, entre os membros do NEPRES, concorreu para o surgimento do Núcleo Gestor que está encarregado de deliberar sobre os temas que serão objeto de estudo do núcleo, bem como a respeito da admissibilidade dos casos que são encaminhados com o pedido de realização de práticas restaurativas. Também é por meio do Grupo Gestor que é realizada a gestão e o arquivamento dos documentos relacionados com os facilitadores e com as práticas restaurativas, promovendo o envio de relatórios mensais ao Serviço de Justiça Restaurativa do Tribunal de Justiça do Estado de São Paulo a respeitos de práticas restaurativas relacionadas com processos em trâmite.

Com este modelo de gestão e estratégia implantada, o NEPRES iniciou o segundo semestre do ano de 2018 com um planejamento mais amplo, com o objetivo de promover a capacitação de novos facilitadores e de debater temas que se demonstraram relevantes na cidade de Socorro, o que será apresentado a seguir. 


\section{O primeiro curso de formação de facilitadores em prática restaurativa com ênfase em processos circulares na Cidade e Socorro}

\subsection{Apresentando a Justiça Restaurativa}

O Primeiro Curso de Formação de Facilitadores em Prática Restaurativa com ênfase em Processos Circulares, promovido pelo NEPRES, disponibilizou quinze vagas abertas ao público em geral, além de facultar aos facilitadores a participação como supervisão por meio da publicação de edital com regras claras do curso, inclusive em relação à gratuidade das aulas.

O objetivo do curso foi promover a conscientização sobre o que é a Justiça Restaurativa e permitir o desenvolvimento do conhecimento e da capacidade de aplicar os processos circulares em situações conflitivas ou não, por meio de um processo que prioriza o diálogo e a construção de um espaço seguro para que sejam discutidas as necessidades das pessoas e as obrigações necessárias para que seja possível manter a cooperação social.

Na primeira parte do curso, o esforço foi para demonstrar aos participantes que a análise sobre o que é a Justiça Restaurativa exige uma reflexão sobre uma das perguntas mais antigas da humanidade: o que é a justiça? Esta é uma importante reflexão que deve ser feita constantemente, pois exige um olhar para dentro de nós e que pode revelar a nossa compreensão sobre o que é justo ou injusto, certo ou errado, bom ou mau.

De um modo geral, as respostas apresentadas para a pergunta demonstram que o que prevalece é um sentido subjetivo a respeito do que é a justiça de modo que definição de uma pessoa pode entrar em conflito com a de outra. Por esta razão optou-se por iniciar o curso analisando as diversas compreensões existentes entre os participantes, por meio de uma atividade onde deveriam escrever ou desenhar como a justiça é vista e como a justiça é sentida.

Após a atividade apresentada, mesmo que as definições do que é a justiça não tenham ganhando um sentido absoluto, foi possível observar a conscientização da importância de se pensar sobre a justiça, bem como de que a Justiça Restaurativa surge neste cenário, de inexistência de uma resposta absoluta, como uma teoria que compõe o rol de ideias que existem no mundo que tentam explicar o motivo pelo qual devemos 
mantermos unidos e em cooperação para a estabilidade social.

Procurando expor aos participantes um pouco da visão da comunidade internacional, foi apresentado no curso de formação a perspectiva da Justiça Restaurativa como uma ideia de justiça que está ligada com os movimentos sociais e com a necessidade de repensarmos a maneira de como lidamos com as situações de conflito, o que inclui o debate sobre as políticas públicas que são dirigidas por nossas instituições e que são orientadas por uma legislação escrita e apoiada pelos diversos atores da vida pública. Esta perspectiva apresentada no curso, representa o fundamento da corrente que interpreta a Justiça Restaurativa como uma teoria a partir de uma abordagem filosófica ao invés de apenas um conjunto de práticas ou técnicas.

Além da corrente destacada, foi apresentado aos participantes do curso que existem outras teorias que procuram interpretar a Justiça Restaurativa como uma visão "expansionistas" ${ }^{4}$ ou "maximalista" ${ }^{5}$. No entendimento destas correntes, a Justiça Restaurativa pode ser interpretada como uma prática ou uma técnica que se define por meio do resultado idealizado - pela reparação do dano individual, restauração do relacionamento e da confiança social nas situações em que um dano tenha ocorrido.

Como fechamento da primeira parte do curso, apresentou-se aos participantes do curso a corrente de pensamento que é denominada como a "pura". Nesta corrente encontram-se filiados Braithwaite, Richard, Johnstone, McCold e Marshall, nomes que constantemente são citados em pesquisas sobre justiça restaurativa no Brasil. Para esta corrente, argumenta-se que a Justiça Restaurativa pode ser definida como um artificio caracterizado pela mediação entre pessoas que sofreram algum tipo de dano, em uma ou várias reuniões, facilitada por uma ou mais pessoas que consigam exercer a tarefa de modo imparcial. Marshall, por exemplo, defende que a Justiça Restaurativa deve ser compreendida como um procedimento pelo qual as pessoas afetadas por um dano decidem coletivamente como lidar com as consequências do presente e do futuro causadas pelo dano.

\footnotetext{
${ }^{4}$ CLAMP, K. e PATERSON, C. Restorative Policing: Concepts, Theory and Practice. Londres: Routledge, 2017, pág. 27.

${ }^{5}$ WALGRAVE, L. How pure can a maximalist approach to restorative justice remain? Or can a purist model of restorative justice become maximalist? Bélgica: Contemporary Justice Review, 3(4), pp. 415-432.
} 


\subsection{Circular Ensinando a Prática}

Na segunda parte do curso, foi apresentado para os participantes a Prática Circular como sendo um tipo de prática restaurativa versátil, que pode ser usada proativamente para construir relacionamentos e comunidades, ou reativamente como resposta para situações conflitos. Procurou-se esclarecer, que a Prática Circular dá às pessoas a oportunidade de uma fala e escuta ativa, em uma atmosfera de segurança, decoro e igualdade. O objetivo também foi de conscientizar os participantes de que a Prática Circular permite que as pessoas troquem suas histórias e ofereçam suas próprias perspectivas a respeito dos fatos vivenciados.

Destacou-se ainda, que por meio da Prática Circular é possível propor a resolução de conflitos, a superação de traumas, o suporte em situações difíceis, a tomada de decisão, a troca de informações e o desenvolvimento de relacionamentos. Aos participantes, foi esclarecido que a prática circular também pode figurar como uma alternativa aos processos contemporâneos de reuniões, que muitas vezes dependem da hierarquia, do posicionamento e do jogo de ganhar e perder por meio do melhor argumento, portanto, sendo possível de ser utilizada em qualquer ambiente organizacional, institucional ou comunitário.

A partir da difusão destas informações, em uma visão geral, estimulou-se aos participantes a compreensão de que a Prática Circular é como um caminho que deve ser percorrido em conjunto, para que seja possível que todos sejam respeitados, que tenham a chance de falar sem ser interrompido, expressem quem realmente, dividam experiências e histórias, desfrutem da condição de igualdade - ninguém sendo mais importante que o outro, expressem a espiritualidade e suas emoções.

Ainda promovendo uma visão geral, esclareceu-se aos alunos que o círculo pode ser útil quando mais de uma pessoa necessita tomar uma decisão em conjunto, superar um desentendimento, expressar alguma experiência dolorosa, formar um grupo de trabalho, compartilhar dificuldades ou apenas para compartilhar histórias e apreender com as experiências vividas por outras pessoas. Destacou-se, que a Prática Circular é capaz de promover um espaço seguro onde podem ser enfrentadas questões como a raiva, o ódio, a frustração, a dor, o conflito pessoal ou com outras pessoas, a diversidade de 
visões sobre o mundo, a angústia, o silêncio, o paradoxo, a alegria e a confiança.

Ademais, aos participantes do curso foi oferecida uma análise da origem da Prática Circular, expondo que ela foi pensada e desenvolvida a partir dos Círculos de Conversação, muito comum na cultura dos povos indígenas que vivam na América do Norte, ocasião em que eram apresentadas questões importantes para a tribo e que precisavam ser melhor compreendidas ou resolvidas, e que atualmente, foi apresentada também, de que a Prática Circular, atualmente, tem sido denominada como Círculos de Paz ou Círculos de Pacificação, após ser identificada a sua utilização em 1991 em algumas comunidades do Canadá, especialmente, quando foi utilizada por Juízes e Comissões de Justiça na solução de casos no Território de Yukon. Já nos Estados Unidos, a Prática Circular surgiu a partir de um projeto-piloto em Minnesota que visava auxiliar jovens e adultos que haviam praticado crimes.

Na sequência do curso, foi percorrido o caminho em busca da formulação do conceito da Prática Circular, e com sucesso, os participantes conseguiram elaborar um conceito para definir a Prática Circular: como sendo uma prática ou técnica holística que é guiada por ritos ou procedimentos com o objetivo de conectar as pessoas; de que é um procedimento dialógico desenvolvido em um espaço seguro, auxiliado por um ou mais facilitadores, e que permite que todos os participantes tenham igual oportunidade de falare contribuir para a solução do conflito. Assim, ficou compreendido que o processo circular baseia-se nas premissas de que todos os seres humanos desejam estar conectados aos outros por meio de um relacionamento saudável, e, também, que todos são capazes de compartilhar valores fundamentais que possam indicar o caminho para a construção de um relacionamento saudável.

A Prática Circular, na forma apresentada no curso, teve como objetivo estimular o sentimento de humanidade que existe em nós, e partir desta base, construirmos uma resposta não violenta para os conflitos que se apresentam na convivência diária. O que se propôs aos alunos, foi a reflexão e oportunidade de modificar a abordagem fundada na coerção para uma perspectiva que prioriza a compreensão do outro e soluções de conflitos a parti do compartilhamento de responsabilidades.

Buscando uma melhor assimilação do conteúdo, apresentou-se também aos par- 
ticipantes do curso o entendimento de que o Prática Circular funciona a partir de uma estrutura pré-definida que possibilita o exercício da liberdade de falar a nossa verdade, de retirarmos as "máscaras" e proteções que escondem os nossos verdadeiros sentimentos e visão sobre o mundo, de tratar uns aos outros como um ser humano, de revelar nossos medos e reconhecer nossos erros, de agir de acordo com nossos valores.

Destacou-se, que em um processo circular os participantes se sentam em círculo, deixando o centro do círculo sem qualquer obstáculo (mesa, cadeira e etc.), e que o formato circular simboliza um espaço criado onde não existe uma hierarquia ou liderança, uma vez que todos exercem como igualdade a liderança dos rumos que o círculo poderá tomar. Também, foi ensinado que é possível colocar no centro do círculo objetos que carreguem algum significado para o grupo, para que os participantes olhem para ele e sempre se lembrem dos valores que foram compartilhados por todos.

A respeito da estrutura da Prática Circular, buscou-se demonstrar aos alunos que ela é constituída por uma cerimônia de abertura e fechamento, objeto da palavra, facilitador ou guardião, compartilhamento de valores e de diretrizes do grupo e da formação de consenso, nos casos quem envolva a tomada de uma decisão. Neste contexto, foi explorado o tema no sentido de que todos pudessem compreender que a Prática Circular pode ser realizada com uma variedade de objetivos, podendo ser realizada uma distinção entre eles com a finalidade de compreender a função que está sendo exercida pelos facilitadores.

a) Círculo para conversação: Os participantes escolhem uma questão ou tópico de interesse e discutem as diversas perspectivas sobre o assunto.

b) Círculo para compreensão de um conflito ou situação difícil: Os participantes focam na compreensão de algum aspecto do conflito ou situação difícil, não sendo necessário a busca por um consenso.

c) Círculo para cura: Os participantes compartilham a dor com outras pessoas falando sobre a situação traumática ou de perda. Não é obrigatório, contudo, se recomenda que neste tipo de círculo seja elaborado um plano de suporte para as pessoas que sofrem com a dor.

d) Círculo para sentenciar: Os participantes auxiliam o sistema de justiça na tomada de decisão a respeito de um caso em que tenha ocorrido um dano. Esta prática envolve todas as pessoas que tenham sofrido direta ou indiretamente um dano. Nesta modalidade de círculo participam as pessoas que causaram o dano, as pessoas que sofreram o dano, famílias e amigos, membros da comunidade, representantes do sistema de justiça (advogados, juízes, promotores, polícia) e outros profissionais, como por exemplo, psicólogos, assistentes sociais e etc.

e) Círculo para dar suporte: Os participantes deste círculo são con- 
siderados como uma ?peça chave? para dar suporte a uma ou mais pessoas que está passando por uma situação de dificuldade ou por uma grande mudança em sua vida. Normalmente esta modalidade de círculo mantém encontros regulares entre os participantes pelo período necessário para que a situação de dificuldade seja superada ou a mudança de vida seja bem assimilada.

f) Círculo para construção de uma comunidade: Os participantes se reúnem em razão de um interesse em comum e com a finalidade de construírem um relacionamento, para que seja possível dar suporte para as decisões coletivas e para as ações necessárias a partir da ideia da responsabilidade compartilhada.

g) Círculo para solução de um conflito: Os participantes procuram esta modalidade de círculo para resolver suas diferenças. A solução é alcançada quando as partes conseguem chegar a um consenso.

h) Círculo para reintegração de pessoas: Neste círculo participam um indivíduo, um grupo ou uma comunidade com o objetivo de promover a reintegração de um ou mais indivíduos no contexto social em que tenha sido afastado ou banido.

i) Círculo para celebração: Os participantes se reúnem para reconhecer um indivíduo ou um grupo de pessoas, bem como para celebrar uma alegria que pode ser compartilhada.

Ainda no mesmo sentido, após compreendermos a diversidade de círculos que existem, foram apresentadas as possibilidades de aplicação da Prática Circular:

a) Seja necessário o suporte ou assistência para as pessoas que sofreram um dano;

b) Seja necessário elaborar uma sentença em caso que envolva jovens ou adultos que tenham causado algum dano;

c) Necessite promover a reintegração de uma pessoa na comunidade após um período preso;

d) Seja necessário o monitoramento e suporte para pessoas que demonstrem um perfil de reincidência criminal;

e) Seja necessário promover o suporte para familiares que sofreram a perda de um ente querido em razão de um crime;

f) Seja necessário promover o monitoramento e suporte para um acusado de cometer abuso contra crianças ou de ser negligente no cuidado e segurança da criança;

g) Seja necessária a construção de uma equipe de trabalho;

h) Seja necessário o desenvolvimento de estratégias ou planos em conjunto com organizações;

i) Seja necessário o desenvolvimento de um programa para o funcionamento de um órgão, instituição ou organização;

j) Seja necessário enfrentar a discriminação, assédio e conflitos pessoais no ambiente de trabalho;

k) Seja necessária a solução de desentendimento entre vizinhos; I) Seja necessário resolver brigas em salas de aulas ou em espaços de recreação;

m) Seja necessária uma atuação disciplinar nas escolas;

n) Seja necessária a promoção de uma nova forma para ensinar alunos com dificuldades;

o) Seja necessário o apoio para usuários de drogas ou álcool;

p) Seja necessário o desenvolvimento de um novo plano de educação;

q) Seja necessária a solução de conflito familiar;

r) Seja necessária a abertura de diálogo entre imigrantes e nacionais; 
s) Seja necessária a abertura de diálogo entre gangues para a pacificação de uma comunidade;

t) Seja necessária a celebração de um aniversário ou outras datas e eventos especiais;

A parte teórica foi necessária para que os integrantes entendem-se a base que fundamenta as Práticas Circulares. Contudo, o curso também focou na realização das práticas em si, para que situações como a vivenciada após a formação do primeiro grupo não ocorressem novamente, de forma que eles estariam melhor organizados e preparados para a atuação.

Para tanto, foi feito uma prática circular com a finalidade de desenvolver o papel do facilitador no círculo por meio do desenvolvimento lúdico dos crachás e também de um quebra-gelo para apresentação. Por ter sido o primeiro círculo de várias pessoas, passamos por todas as etapas do círculo com explicação de seus significados: peça de centro, cerimônia de abertura, check-in, formulação de diretrizes, atividade principal, check-out, cerimônia de encerramento.

Foram desenvolvidas ainda as competências de buscar perguntas balizadoras, pré-círculos e pós-círculos, bem como discussão de casos e estruturação do formato desde o pré-círculo, círculo e pós-círculo.

Por fim, os alunos tiveram de realizar círculos com base no desenvolvimento da auto-estima, segurança, confiança, criatividade e a responsabilização coletiva com divisão do tempo e do espaço de fala. A última etapa do curso foi a realização dos círculos de homenagem, no qual eles tiveram de organizar todo o círculo e convites para homenagear um cidadão socorrense.

\subsection{Conclusão}

O curso desenvolvido para ensinar a Prática Circular foi desenvolvido a partir da ideia de que precisamos nos ajudar a acessar a nossa humanidade e a partir dela encontrar uma forma saudável de lidar com as situações de conflito - o que inclui as situações em que exista um dano. Nesta perspectiva surgiram algumas questões que importantes que precisam ser respondidas: Como podemos conviver sem causarmos danos uns aos outros? Caso não seja possível conviver sem causarmos danos, o que devemos fazer quando ele ocorrer? 
A resposta apresentada aos alunos apresentou o argumento de que não podemos viver em comunidade sem causar danos uns aos outros, e que a solução mais comum, nas sociedades ocidentais, é a imposição de uma sanção sobre o indivíduo de modo quesirva para responsabilizar e desencorajar outros indivíduos de praticar o mesmo ato. É a utilização da coercitividade e da coação no controle do comportamento social.

Em contraposição ao modelo comum, é possível pensar na Prática Circular como uma alternativa prática para a introdução da Justiça Restaurativa como ideal de justiça em uma sociedade que não deseja depender da coercitividade e coação. A principal ideia é de que não é saudável o exercício do poder sobre as pessoas, mas sim de um poder compartilhado (com) entre as diversas pessoas que pertencem a uma sociedade; um posicionamento de que todo ser humano é confiável e importante na construção de soluções para o melhoramento do convívio social.

É por esta razão que, no curso ministrado em Socorro, apresentou-se como fundamento da Prática Circular a busca por uma convivência harmoniosa, explorando o potencial de cada ser humano para construir ou melhorar uma determinada sociedade ou comunidade. Portanto, na prática circular busca-se a formação de relacionamentos saudáveis de modo que seja possível manter entre os indivíduos um bom comportamento e uma cooperação para manter a coletividade a salvo, sempre procurando minimizar os conflitos que surgem em razão da convivência.

Argumentou-se também, que na sua essência a Prática Circular procura responder: como devemos agir para conseguirmos relacionamentos saudáveis? O que pode ser feito para reparar um dano imediato e para prevenir situações no futuro? Quais são as ofensas e circunstâncias, do passado ou do presente, que nos motivam a buscar relacionamentos mais saudáveis? Quais passos podemos dar para compreender as ofensas e procurar uma forma saudável de supera-las? No processo de aprendizado, destacouse aos alunos que não existe um caminho certo para responder estas questões, contudo, é possível guiar-se por meio de valores para não se perder na trajetória.

Ao final do curso, o que se buscou foi reiterar que os valores que inspiram a Justiça Restaurativa, e a Prática Circular, cooperam para que um determinado conflito seja analisado a partir da perspectiva de uma oportunidade de nos conhecermos melhor, de 
compartilhar sabedoria e pensar sobre o relacionamento humano. De que são os valores que trazemos para o círculo que podem revelar a forma como lidamos com as situações de conflito ou dano, sendo esta a razão para que, antes de avançar sobre qualquer conflito, tenhamos a cautela de ter muito claro quais são os valores que realmente aceitamos em nossas vidas e que nos orientam no sentido de buscar forças para ajudar uma ou mais pessoas a superar as suas diferenças da melhor maneira possível.

\section{Os resultados do NEPRES após o primeiro curso de formação de facilitadores}

Após a capacitação dos voluntários em Práticas Circulares, a cidade de Socorro/SP passou a ter 22 (vinte e dois) facilitadores aptos para atuar em círculos de construção de paz e contribuir com a sensibilização dos diversos segmentos da sociedade sobre a importância da Justiça Restaurativa.

Com este importante avanço, o NEPRES tornou-se um projeto capaz de promover ações que podem contribuir com a transformação das comunidades que vivenciam situações de conflitos e de violência todos os dias, por meio da criação de espaços seguros para o diálogo sobre questões importantes e tomada de decisões que podem modificar os rumos de uma vida.

Assim, o NEPRES foi reorganizado e restruturado para criar espaços que possibilitem a realização de círculos restaurativos a pedido dos cidadãos ou encaminhados pelo sistema de justiça da cidade. Ao receber o encaminhamento do caso concreto, o Grupo Gestor do NEPRES analisa a possibilidade ou não do caso ser submetido à Prática Circular. Na hipótese de o caso ser recebido, o Grupo Gestor promove o encaminhamento do caso para os facilitadores designados, este que serão os responsáveis pela organização do espaço em que será realizada a Prática Circular, da sensibilização das partes envolvidas a respeito do projeto e por assegurar que os participantes estejam envolvidos com o círculo de forma voluntária. Nos casos judicializados, se eventualmente for possível estabelecer um consenso entre as partes envolvidas, é lavrada uma Ata com o resumo do consenso das partes e encaminhada para o juízo competente que poderá homologar por meio da sentença.

Neste período de amadurecimento, do projeto implantado na cidade de So- 
corro/SP, foi possível perceber alguns avanços significativos com os seguintes atos realizados e já agendados:

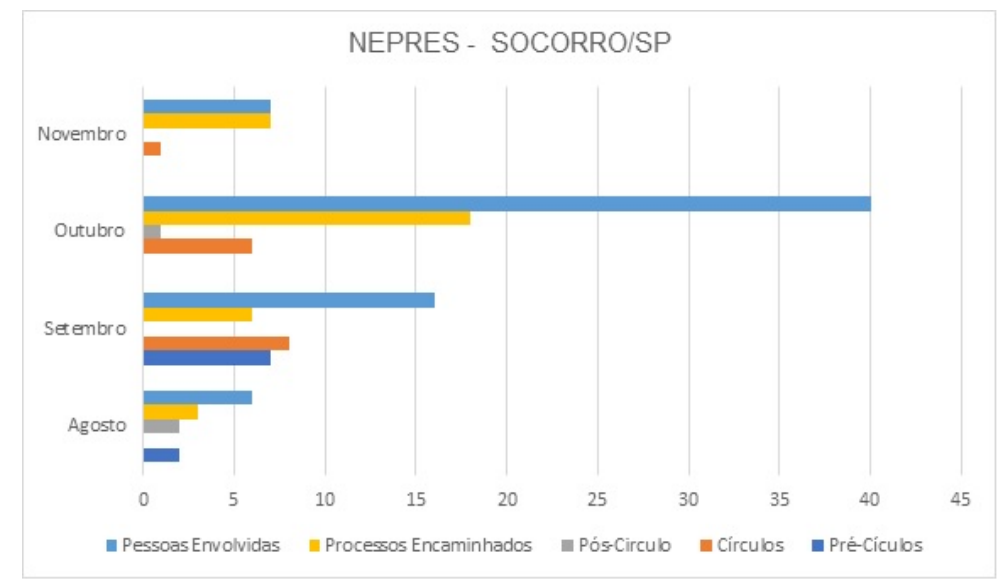

Figura 1. NEPRES - SOCORRO/SP

Fonte: NEPRES/Formulário de Levantamento Estatístico da Justiça Restaurativa - TJSP, ANO: 2018.

Passado o primeiro curso de formação promovido na cidade de Socorro/SP, e superadas as dificuldades pelas quais o projeto foi submetido para promover a formação, verifica-se o quanto foi importante o pulso firme para manter o treinamento na cidade, com a destinação de um treinamento voltado para as complexidades enfrentadas pela comunidade local, dando apoio e incentivo para toda e qualquer pessoa que se interesse em auxiliar no processo de construção de paz.

Também foi possível atestar que a inexistência de parceria com órgãos estatais e de recursos financeiros não foi um impeditivo para a comunidade de Socorro se mobilizar em busca da formação. Do mesmo modo, constatou-se que a formação proporcionada representou um significativo avanço na abordagem dos conflitos existentes na cidade de modo que onde a implementação da Justiça Restaurativa se mostrou presente ocorreram mudanças substantivas na construção de uma efetiva Cultura de Paz.

O projeto de implantação do NEPRES na cidade de Socorro/SP, deixa claro, que, para além da necessidade de implementação de iniciativas para a construção de uma cultura de paz, importa perceber que a implementação de um projeto de Justiça Restaurativa nos mostra que não é possível refletir ou agir sobre o conflito ou violência sem entrar na discussão sobre o que é justiça e quais são as necessidades 


\section{Referências}

BRAITHWAITE, J. Setting standards for restorative justice. British Journal of Criminology: 2002.

CLAMP, K. e PATERSON, C. Restorative Policing: Concepts, Theory and Practice. Londres: Routledge: 2017.

GAVRIELIDES, T. Restorative Justice Theory and Practice: Addressing the Discrepancy. Helsinki: European Institute for Crime Prevention and Control: 2007.

LEDERACH, John Paul. Transformação de Conflitos. São Paulo: Palas Athena: 2013.

MAIA, Diego Dall' Agnol. A ideia de uma justiça restaurativa. Caxias do Sul: JurisPlenum: 2018.

PALI, B. Restorative Justice and Social Justice - Paper presented at the European Forum for Restorative Justice Conference in Belfast. Belfast: 2014.

PAVLICH, G. Ethics, Universal Principles and Restorative Justice. In: G. Johnstone \& D. Van Ness, eds. Handbook of Restorative Justice. Cullompton: Willan Publishing: 2007.

PRANIS, Kay e BOYES-WATSON, Carolyn. No coração da esperança: guia de práticas circulares: o uso de círculos de construção da paz para desenvolver a inteligência emocional, promover a cura e construir relacionamentos saudáveis. Tradução: Fátima de Bastiani. Porto Alegre: Tribunal de Justiça do Estado do Rio Grande do Sul, Departamento de Artes Gráficas, 2011. 280 p.

PRANIS, Kay. Círculos de justiça restaurativa e de construção de paz: guia do facilitador. Tradução: Fátima de Bastiani. Porto Alegre: Escola Superior da Magistratura da AJURIS / Associação dos Juízes do Rio Grande do Sul / Projeto Justiça para o Século 21: 2011.

PRANIS, Kay. Processos Circulares. São Paulo: Palas Athena: 2010.

ROSENBERG, Marshall B. Comunicação Não Violenta: técnicas para aprimorar relacionamentos pessoais e profissionais. São Paulo: Editora Agora: 2006.

SAWATSKY, J. Justpeace Ethics: A Guide to Restorative Justice and Peacebuilding. Eugene: Cascade Books: 2008.

SHAPLAND, J. et al. Restorative Justice: The Views of Victims and Offenders - The Third Report from the Evaluation of Three Schemes: 2007.

STAHLKOPF, C. Restorative justice, rhetoric, or reality? Conferencing with young offenders. Contemporary Justice Review: 2009.

UNIDAS, Nações. Objetivos do Desenvolvimento Sustentável. $2015 . \quad$ Disponível em: <https://nacoesunidas.org/conheca-os-novos-17-objetivos-de-desenvolvimentosustentavel-da-onu/>. Acesso em: 18 set. 2018.

VANFRAECHEM, I. Restorative policing: In pursuit of principles. Journal of Police Studies: 2009.

WALGRAVE, L. How pure can a maximalist approach to restorative justice remain? Or can a purist model of restorative justice become maximalist? Bélgica: Contemporary Justice Review, 3(4), pp. 415-432. 
WOOLFORD, Andrew. The Politics of Restorative Justice. Canada: Fernwood Publishing: 1971.

ZEHR, H. \& Mika, H. Fundamental concepts of restorative justice. Contemporary Justice Review: 1998.

ZEHR, H. Changing Lenses: A New Focus for Crime and Justice. Scottdale: Herald Press: 1990.

ZEHR, Howard. Justiça Restaurativa. São Paulo: Palas Athena: 2013.

ZEHR, Howard. The Little Book of Restorative Justice. Canada: Good Books: 2015.

ZEHR, Howard. Trocando as Lentes: um novo foco sobre o crime e a justiça restaurativa. 25ạ. Ed. São Paulo: Palas Athena: 2018. 